\title{
Radioembolization for neuroendocrine liver metastases is safe and effective prior to major hepatic resection
}

\author{
Florian Bösch ${ }^{1,2}$, Harun Ilhan ${ }^{2,3}$, Vanessa Pfahler ${ }^{2,4}$, Michael Thomas ${ }^{1,2}$, Thomas Knösel ${ }^{2,5}$, Valentin Eibl ${ }^{1,2}$, \\ Sebastian Pratschke ${ }^{1,2}$, Peter Bartenstein ${ }^{2,3}$, Max Seidensticker ${ }^{2,4}$, Christoph J. Auernhammer ${ }^{2,6}$, \\ Christine Spitzweg ${ }^{2,6}$, Markus O. Guba ${ }^{1,2}$, Jens Werner ${ }^{1,2}$, Martin K. Angele , $^{1,2}$ \\ ${ }^{1}$ Department of General, Visceral, and Transplant Surgery, Ludwig-Maximilians-University Munich, Munich, Germany; ${ }^{2}$ Interdisciplinary Center \\ of Neuroendocrine Tumors of the GastroEnteroPancreatic System, Ludwig-Maximilians-University Munich, Munich, Germany; ${ }^{3}$ Department \\ of Nuclear Medicine, University Hospital, Ludwig-Maximilians-University Munich, Munich, Germany; ${ }^{4}$ Department of Radiology, ${ }^{5}$ Institute of \\ Pathology, ${ }^{6}$ Department of Internal Medicine 4, Ludwig-Maximilians-University Munich, Munich, Germany \\ Contributions: (I) Conception and design: F Bösch, MK Angele; (II) Administrative support: P Bartenstein, MO Guba, J Werner; (III) Provision \\ of study material or patients: P Bartenstein, CJ Auernhammer, C Spitzweg, J Werner; (IV) Collection and assembly of data: F Bösch, H Ilhan, V \\ Pfahler, M Thomas, T Knösel, V Eibl; (V) Data analysis and interpretation: F Bösch, S Pratschke; (VI) Manuscript writing: All authors; (VII) Final \\ approval of manuscript: All authors. \\ Correspondence to: Martin K. Angele. Department of General, Visceral, and Transplant Surgery, Ludwig-Maximilians-University Munich, \\ Marchioninistr. 15, 81377 Munich, Germany. Email: martin.angele@med.uni-muenchen.de.
}

Background: Radioembolization (RE) is well established in the treatment of neuroendocrine liver metastases. However surgery is rarely performed after RE, although liver resection is the gold standard in the treatment of localized neuroendocrine liver metastases. Therefore, aim of the present study was to evaluate the safety and feasibility of liver resection after RE in a homogenous cohort.

Methods: From a prospective surgical $(n=494)$ and nuclear medical $(n=138)$ database patients with NELM who underwent liver resection and/or RE were evaluated. Between September 2011 and December 2017 eight patients could be identified who underwent liver resection after RE (mean therapeutic activity of 1,746 Mbq). Overall and progression free survival were evaluated as well as epidemiological and perioperative factors. The surgical specimens were analyzed for necrosis, fibrosis, inflammation, and steatosis.

Results: The mean hepatic tumor load of patients, who had liver surgery after RE, was $31.4 \%$ with a mean Ki-67 proliferation index of 5.9\%. The majority of these patients (7/8) received whole liver RE prior to liver resection, which did not increase morbidity and mortality compared to a surgical collective. Indications for RE were oncological (6/8) or carcinoid syndrome associated reasons (2/8). Mean overall survival was 25.1 months after RE and subsequent surgery. Tumor necrosis in radioembolized lesions was $29.4 \%$ without evidence of fibrosis and inflammation in hepatic tissue.

Conclusions: This is the first study analyzing the multimodal therapeutic approach of liver resection following whole liver RE. This treatment algorithm is safe, does not lead to an increased morbidity and is associated with a favorable oncological outcome. Nonetheless, patient selection remains a key issue.

Keywords: Radioembolization (RE); neuroendocrine tumor; liver surgery

Submitted Jan 20, 2019. Accepted for publication May 17, 2019.

doi: 10.21037/hbsn.2019.07.11

View this article at: http://dx.doi.org/10.21037/hbsn.2019.07.11

\section{Introduction}

Liver metastases of neuroendocrine tumors (NELM) are common and frequently lead to initial diagnosis (1). Even patients with small primary tumors might have a profound hepatic tumor load $(2,3)$. Liver surgery is the gold standard in the treatment of localized liver metastases since resection 
provides a chance of cure (4-6). In case of diffuse hepatic metastatic disease surgery might not be feasible. In those patients, the therapeutic approach has to be adapted to the clinical situation.

Liver directed transarterial therapies, such as radioembolization (RE), are established for the treatment of patients with diffuse NELM (7-9). NELM are highly vascularized and with $\mathrm{RE}$ a high therapeutic active radiotherapy can be delivered to the liver metastases by the use of yttrium-90. RE prolongs time to progression and survival and can alleviate tumor related symptoms (i.e., carcinoid syndrome, hypoglycemia) (10,11). Additionally, unilateral RE can induce hypertrophy of the contralateral lobe of the liver prior to liver surgery $(12,13)$.

There is only little evidence, if hepatic surgery can safely be performed following RE (14). In particular, no study evaluated the outcome for patients after whole liver SIRT. In this respect, the hepatotoxicity of RE of the future liver remnant (FLR) is not clearly specified since RE was delivered mostly unilaterally in previous studies (14-16). Additionally, no information about the oncological outcome in patients with NELM is given $(14,16)$. In this respect, no previous study analyzed the effect of the multimodal therapeutic approach of liver resection after RE. Therefore, aim of the present study was to evaluate the oncological outcome, safety and feasibility of the multimodal therapeutic approach of liver resection after RE including whole liver RE in a homogenous cohort of patients with NELM.

\section{Methods}

From a prospective surgical database $(n=494)$ and from a prospective nuclear medical database $(n=138)$ patients with NELM were identified who received RE for NELM and/or liver resection between September 2011 to December 2017. Out of these databases eight patients had hepatic surgery after RE, 17 patients underwent only liver surgery and 12 patients received RE without liver surgery. Therapeutic activity was determined according to the modified body surface area (mBSA) method as previously published (17). At the day of RE patients received routinely anti-emetics, corticosteroids and antibiotics (ciprofloxacin). Patients did not get somatostatin analogs prior to RE routinely, but somatostatin analogs were continued in pretreated patients. The pre-treatment tumor burden was assessed according to previously published studies (18-20). In the present manuscript the hepatic tumor load was visually assessed on the basis of CT, MRI and PET/CT scans. In cases where MRI and ${ }^{68} \mathrm{Ga}$-DOTA-TATE PET/CT were performed, tumor volume was assessed in both modalities. More than 25 variables were collected for every patient and subsequently analyzed. The medical history of each patient is complete and almost every parameter analyzed was available; only the values of serological markers [chromogranin A (CgA), serotonin, neuron-specific enolase (NSE)] and 5-hydroxyindoleacetic acid (5-HIAA) are not complete for every patient. Therefore the analyzed numbers of patients regarding tumor markers differ. The therapeutic approach in every case was discussed in a multidisciplinary tumor board.

Postoperative complications were graded according to the classification by Dindo et al. and severe complications were graded as greater or equal than grade 3 a (21). Posthepatectomy liver failure (PHLF) was assessed according to the International Study Group of Liver Surgery (22).

To monitor the oncological outcome serological markers (CgA, serotonin, NSE), 5-HIAA, and postoperative crosssectional imaging were evaluated. Postoperative stating was performed 3, 6, 9, and 12 months after RE or surgery, respectively.

Every resected NELM underwent routine processing at the Institute of Pathology. Additionally, the pathological specimens from patients who received RE prior to liver surgery were further analyzed by a blinded and experienced gastrointestinal pathologist ( $\mathrm{T}$ Knösel) to assess the hepatic injury induced by RE. To assess the response to RE, T Knösel determined the amount of necrosis, fibrosis, inflammation, and steatosis as described recently (23).

Statistical analyses were performed using SPSS v 20.0 for Mac (IBM Corp., Armonk, NY) and Prism 6.0 for Mac (GraphPad Software, Inc., La Jolla, CA). Chi-squared test for categorical parameters was used for univariate analysis (e.g., Ki-67 proliferation index, hepatic tumor load). Mean survival times along with their $95 \%$ confidence intervals (95\% CI) and Kaplan-Meier survival statistics were calculated for the entire sample using Log-Rank tests. P values lower than 0.05 were considered significant.

\section{Results}

\section{Liver resection after $R E$}

Characteristics of the patients $(\mathrm{n}=8)$ included are displayed in Table 1. There were four male and four female patients with a mean age of $60.7(53.8-75.0)$ years. The analyzed cohort was preoperatively classified as American Society of 
Table 1 Patient characteristics (mean values are displayed)

\begin{tabular}{|c|c|c|c|c|c|c|c|c|c|c|c|c|}
\hline Number & $\begin{array}{c}\text { Age } \\
\text { (years) }\end{array}$ & Gender & $\begin{array}{c}\text { ASA } \\
\text { score }\end{array}$ & $\begin{array}{l}\text { MELD } \\
\text { score }\end{array}$ & $\begin{array}{l}\text { Primary } \\
\text { tumor }\end{array}$ & $\begin{array}{c}\text { Ki-67 } \\
\text { primary } \\
\text { tumor }\end{array}$ & $\begin{array}{l}\text { Treatment } \\
\text { prior to RE }\end{array}$ & $\begin{array}{c}\text { Hepatic } \\
\text { tumor } \\
\text { load }\end{array}$ & $\begin{array}{l}\text { Ki-67 liver } \\
\text { metastasis }\end{array}$ & Radioembolization & $\begin{array}{l}\text { RE dose } \\
\text { (MBq) }\end{array}$ & $\begin{array}{l}\text { Time from } \\
\text { RE to surgery } \\
\text { (months) }\end{array}$ \\
\hline 2 & 55.2 & M & 3 & 6 & pNET & 5 & SSA & 1 & 4 & Whole liver & 2,069 & 95.2 \\
\hline 4 & 63.9 & $\mathrm{~F}$ & 3 & 12 & SiNET & 5 & SSA & 60 & 12 & Whole liver & 1,708 & 20.9 \\
\hline 5 & 59.3 & $\mathrm{~F}$ & 3 & 8 & siNET & 1 & SSA & 30 & 1 & Whole liver & 1,696 & 10.9 \\
\hline 6 & 60.2 & $\mathrm{~F}$ & 3 & 6 & Rectum & 5 & none & 30 & 6 & Right lobe, S. IV & 1,828 & 3.1 \\
\hline 7 & 59.0 & $M$ & 3 & 6 & siNET & 5 & SSA & 30 & 5 & Whole liver & 1,754 & 3.3 \\
\hline
\end{tabular}

ASA, American Society of Anesthesiologists; F, female; M, male; MELD, Model of End Stage Liver Disease; n/a, not applicable; pNET, pancreatic neuroendocrine tumor; PRRT, peptide receptor radionuclide therapy; RE, radioembolization; SSA, somatostatin analogs; siNET, small intestine neuroendocrine tumor; TACE, transarterial chemoembolization.

Anesthesiologists (ASA) score of 3 in seven cases and had a mean hepatic tumor load of $31.4 \%$ (1-60\%). The primary site of NELM was a gastrointestinal NET in six cases (75\%) and a pancreas NET in two patients (25\%). Most commonly patients had a G2 primary tumor with a mean proliferation Ki-67 index of $5.9 \%$ (1-20\%). The mean Ki-67 index of the liver metastases was higher and reached $11.4 \%$ (2-50\%). Moreover, the liver metastasis of one patient was classified postoperatively as G3 with a Ki-67 index of 50\%.

The mean $\mathrm{RE}$ therapeutic activity was $1,746 \mathrm{MBq}$ (1,310-2,200 MBq). Indication for RE was hepatic tumor progress in six patients and tumor related symptoms (hypoglycemia, carcinoid syndrome) in two patients. Seven patients received whole liver RE. In one patient RE was applied to the segments IV to VIII to achieve tumor control and hypertrophy of the segments II and III.

The mean time interval between RE and liver surgery was 27.1 months (3.1-95.2 months). Hepatic resection after $\mathrm{RE}$ resulted in complete hepatic tumor clearance in three patients. In the other patients $(n=5)$ tumor debulking with a reduction of the tumor burden to less than $10 \%$ was achieved.

There was no death within 30 days after surgery. Two patients $(25 \%)$, of which one patient was already discharged at the time of diagnosis, had a grade 3 a complication and required percutaneous drainage of a fluid collection. PHLF (grade A) was seen in only one patient and liver function tests had normalized at the time of discharge. The mean hospital stay was 15.3 days (10-26 days).

Evaluation of the pathologic specimens revealed a mean tumor necrosis of $29.4 \%$ (0-60\%) (Figure 1). Within the liver parenchyma treated with $\mathrm{RE}$ almost no inflammation or fibrosis was seen. A correlation between RE therapeutic activity and/or time interval between RE and surgical resection and pathological changes in the tumor or liver tissue was not evident (Table 2).

Following RE CgA levels initially decreased but increased again after 9 to 12 months (fold change after 3 months 0.7, 6 months $0.4,9$ months $0.6,12$ months 1.6). Similarly, serotonin (fold change after 12 months 1.4) and NSE (fold change after 12 months 1.7) serum levels increased following RE. In contrast, liver surgery resulted in longterm decreased CgA (fold change after 12 months 0.4 ), serotonin (fold change after 12 months 0.4 ) and 5-HIAA (fold change after 12 months 0.3 ) levels (Figure $2 A, B, C, D$ ).

\section{Oncological outcome}

Patients with liver resection after RE (group A) were compared to patients who underwent major hepatectomy (group B) and to patients who received $\mathrm{RE}$ alone as treatment for their liver metastases (group C) within the same time period. Patients of the three groups (A-C) did not differ significantly regarding their age, hepatic tumor load, Ki-67 index, ASA score, MELD score, blood loss (A and $\mathrm{B}$ ), duration of the operation (A and $\mathrm{B})$, postoperative 


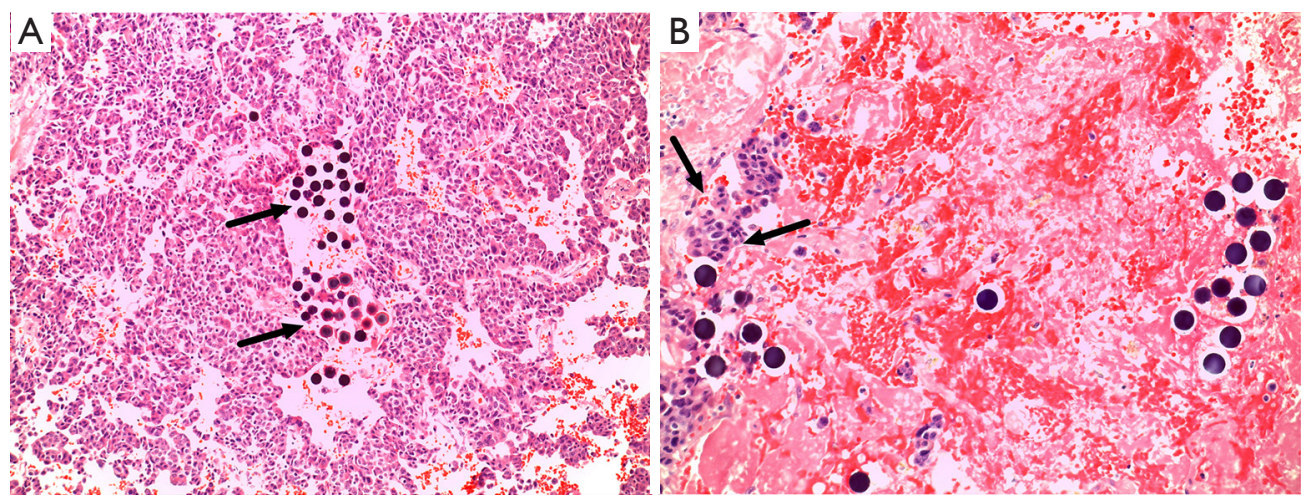

Figure 1 Hematoxylin and eosin (H\&E) stain of liver sections. (A) H\&E stain, 10x magnification; the picture shows microspheres (arrows) in vascular spaces in metastatic parenchyma. (B) H\&E stain, 40× magnification; picture shows microspheres surrounded by necrosis with small amount of viable tumor cells (arrows).

Table 2 Information about surgery and the postoperative course; mean values are displayed. Morbidity is scored according to the classification by Dindo et al.

\begin{tabular}{|c|c|c|c|c|c|c|c|c|c|c|}
\hline Subject & Procedure & $\begin{array}{l}\text { Duration } \\
\text { (min) }\end{array}$ & $\begin{array}{c}\text { Estimated } \\
\text { blood loss }(\mathrm{mL})\end{array}$ & 30-day-morbidity & PHLF & 30-day-mortality & $\begin{array}{c}\text { Tumor } \\
\text { necrosis (\%) }\end{array}$ & $\begin{array}{l}\text { Inflammation } \\
\text { grade }(0-4)\end{array}$ & $\begin{array}{c}\text { Fibrosis } \\
\text { stage }(0-4)\end{array}$ & $\begin{array}{c}\text { Steatosis } \\
(\%)\end{array}$ \\
\hline 1 & SM & 110 & 1,500 & 3 & N/A & $\mathrm{N} / \mathrm{A}$ & 20 & 1 & 0 & 15 \\
\hline 3 & $\mathrm{ERH}, \mathrm{AR}$ & 142 & 600 & 2 & A & $\mathrm{N} / \mathrm{A}$ & 0 & 1 & 0 & 5 \\
\hline 4 & $\mathrm{ERH}, \mathrm{AR}$ & 363 & 2,200 & 0 & N/A & $\mathrm{N} / \mathrm{A}$ & 60 & 1 & 1 & 10 \\
\hline 6 & ERH & 184 & 480 & 0 & N/A & N/A & 20 & 1 & 1 & 0 \\
\hline 7 & SM & 144 & 100 & 0 & N/A & $\mathrm{N} / \mathrm{A}$ & 5 & 1 & 0 & 10 \\
\hline 8 & SM & 188 & 1,600 & 1 & $\mathrm{~N} / \mathrm{A}$ & $\mathrm{N} / \mathrm{A}$ & 60 & 1 & 0 & 5 \\
\hline
\end{tabular}

$\mathrm{AR}$, atypical resection; $\mathrm{ERH}$, extended right hepatectomy; N/A, not applicable; PHLF, posthepatectomy liver failure; SM, segmentectomy $\geq 2$ segments.

complications (A and B), and the length of their hospital stay (A and B) (Table 3).

After hepatic tumor clearance a hepatic recurrence was uncommon and not obvious in group $\mathrm{A}$, but seen in one patient of group B. Taken together, the calculated mean time to hepatic progression was 15.8 months (95\% CI: $8.2-$ 23.5 months) in group A and 32.5 months (95\% CI: $21-$ 44 months) in group B ( $\mathrm{P}>0.05)$ (Figure 3).

Univariate survival analyses were conducted from the date of liver resection and from the date of the first liver directed therapy. If patients were classified regarding the date of liver resection (Figure 4), the calculated mean overall survival for group A was 25.1 months (95\% CI: 13.1-37.1 months) and for group B 71.3 months (95\% CI: 60.4-82.2 months)
$(\mathrm{P}<0.05)$. If patients were classified regarding the date of the first liver directed therapy, the calculated mean overall survival for group A was 60.2 months (95\% CI: 37.183.4 months), for group B 71.3 months (95\% CI: $60.4-$ 82.2 months) and for group C 37.7 months ( $\mathrm{P}>0.05)(95 \%$ CI: 28.5-46.9 months) (Figure 5).

\section{Discussion}

Liver resection is the gold standard in the treatment of localized NELM. However in the case of diffuse hepatic metastases surgery might not be feasible. Nonetheless, tumor debulking might be indicated due to oncological reasons or to alleviate tumor related symptoms (i.e., 
A

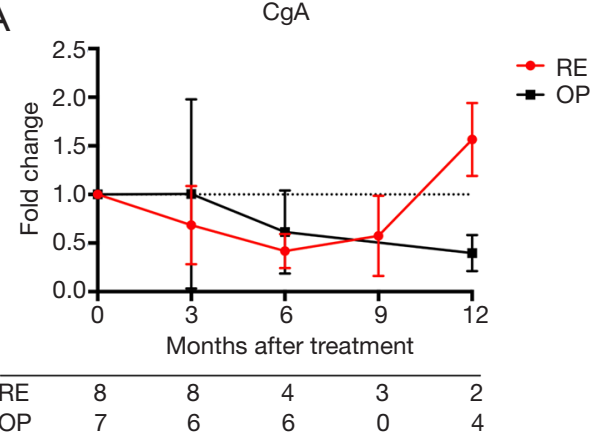

C

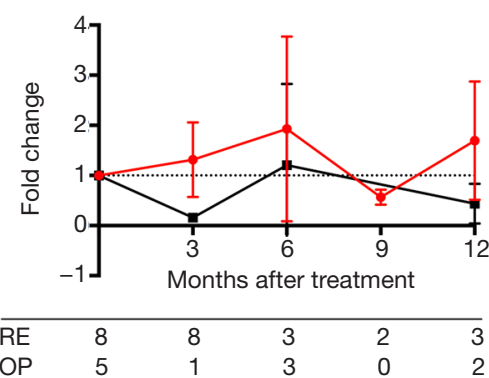

B

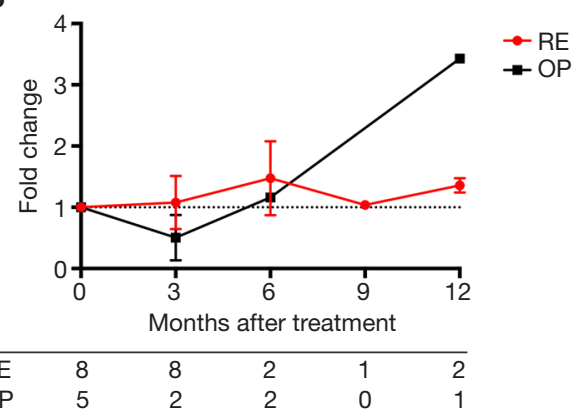

5-HIAA

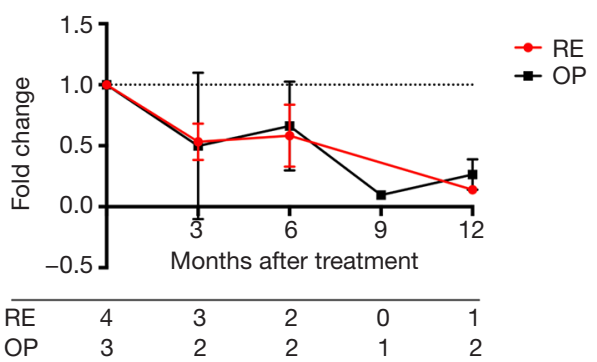

Figure 2 Time course of tumor markers of group A after treatment. The numbers of included values are given below for each marker. 5-HIAA, 5-hydroxyindoleacetic acid; CgA, chromogranin A; NSE, neuron-specific enolase; OP, patients after operation; RE, patients after radioembolization.

Table 3 Patient characteristics of group A (liver resection after radioembolization), group B (liver surgery) and group C (radioembolization); mean values are displayed

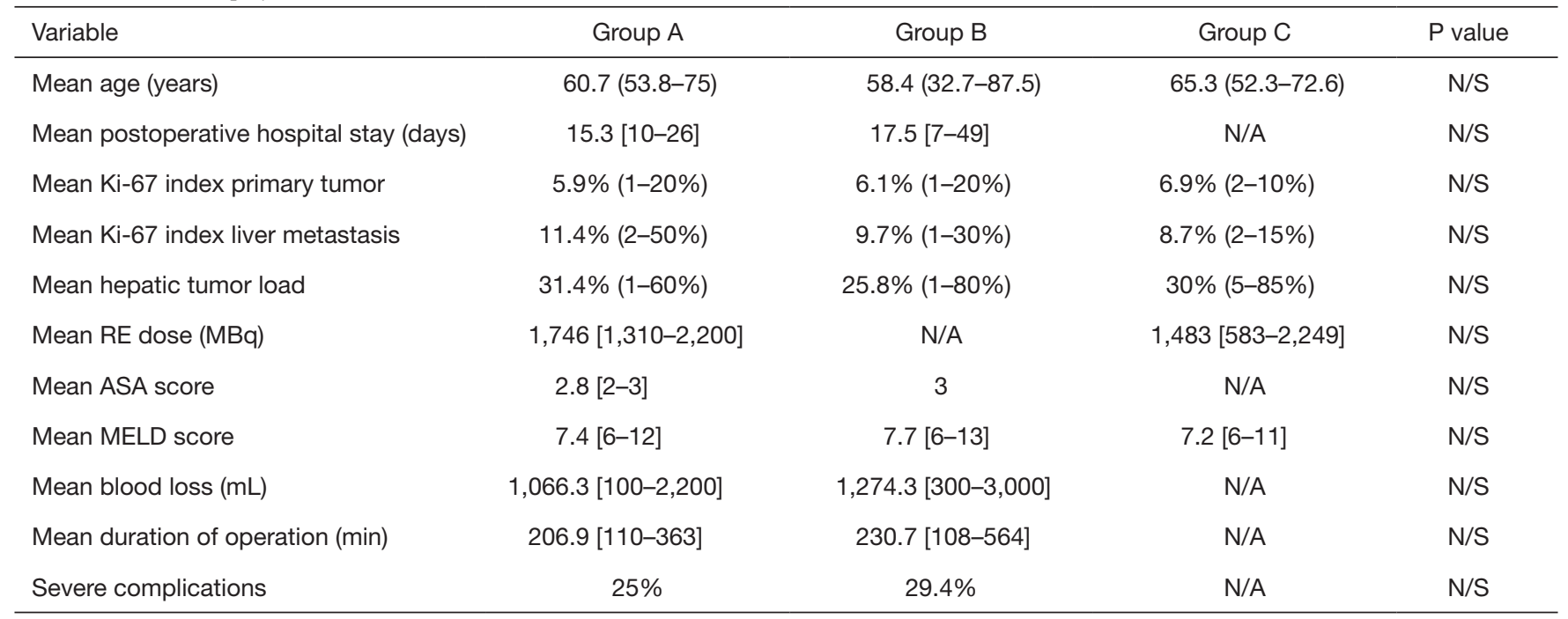

ASA, American Society of Anesthesiologists; MELD, Model of End Stage Liver Disease; min, minutes; mL, milliliter; N/A, not applicable; N/ $S$, not significant. 


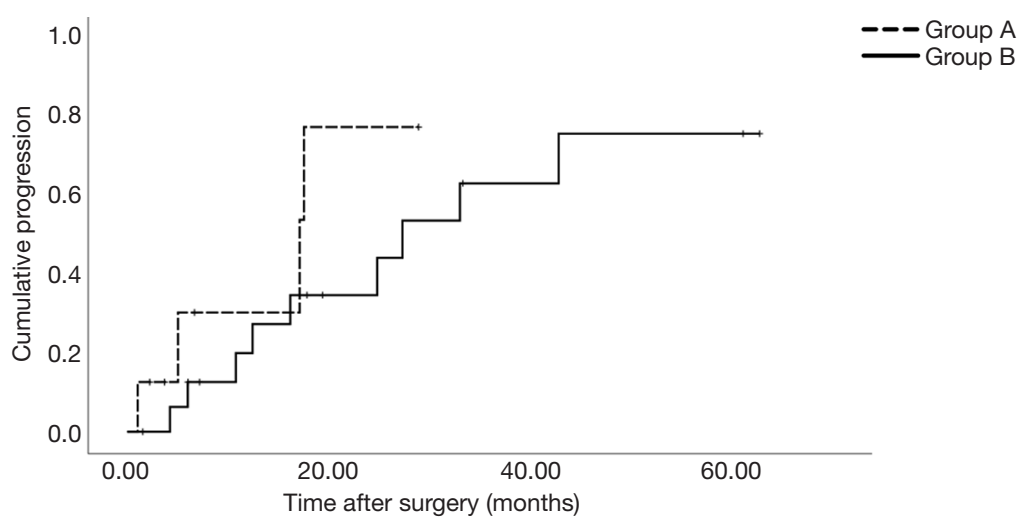

Figure 3 Kaplan-Meier survival analysis displaying the progression free survival $(\mathrm{P}>0.05)$. Group A: liver resection after radioembolization. Group B: liver resection.

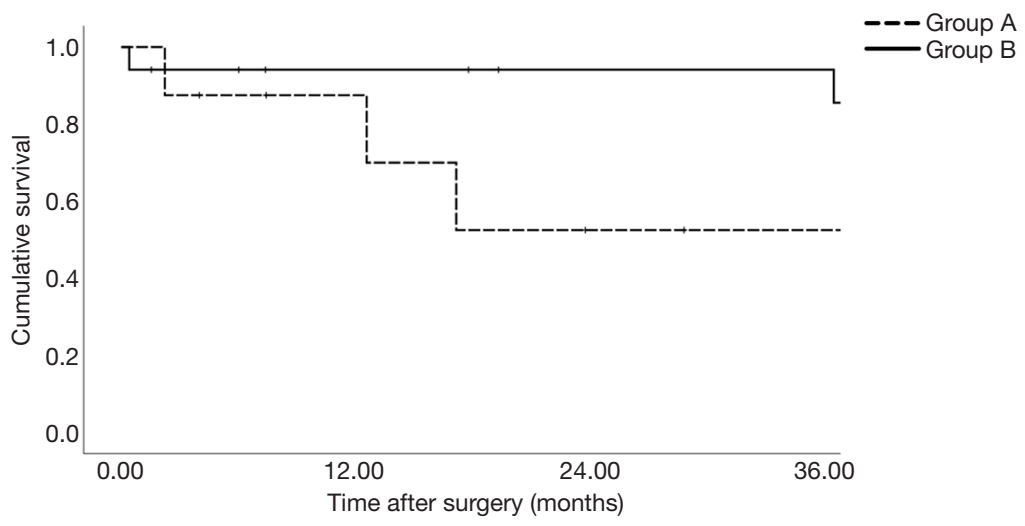

Figure 4 Kaplan-Meier survival analysis displaying the overall survival after surgery $(\mathrm{P}<0.05)$. Group A: liver resection after radioembolization. Group B: liver resection.

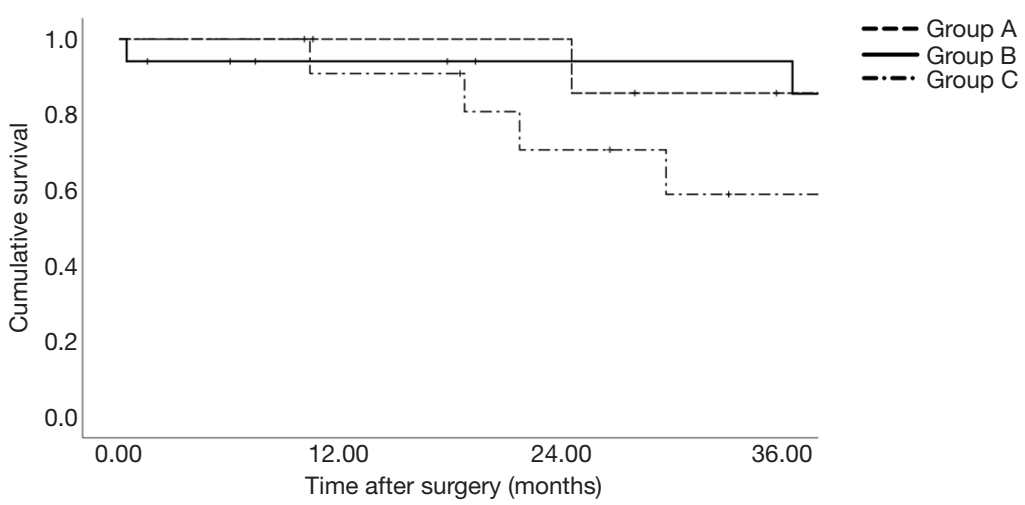

Figure 5 Kaplan-Meier survival analysis displaying the overall survival ( $>>0.05)$. Survival analysis is calculated from the first liver directed therapy. Group A: liver resection after radioembolization. Group B: liver resection. Group C: radioembolization. 
carcinoid syndrome, hypoglycemia) $(5,6)$. Additionally, patients with an extensive hepatic tumor burden might receive liver directed therapy such as $\mathrm{RE}$ (9). There are no reports available which evaluated the safety and efficiency regarding survival for liver surgery after RE. In this respect, this is the first study in which this specific treatment algorithm is analyzed and compared to liver surgery and RE alone.

$\mathrm{RE}$ represents an established therapeutic tool for partial and whole liver treatment in patients with NELM (7-9). Indication for RE is given to achieve oncological tumor control and/or palliate carcinoid syndrome associated symptoms. Patients with diffuse NELM are not considered a priori for hepatic surgery (24), but RE can induce hypertrophy to the FLR (12). Thus, RE may serve as bridging therapy prior to surgery.

In particular in patients with whole organ RE potential detrimental effects to the liver compromising subsequent liver surgery are unclear. In this respect, long-term morphological alterations of hepatic tissue after RE have been demonstrated $(15,25)$. Nonetheless, the results of the present study indicate that major hepatic surgery can be safely performed after whole liver RE. Only one transient PHLF (grade A) and only two severe postoperative complications (both grade 3a) were detected in the eight patients analyzed. Previous studies investigating surgery after RE reported postoperative complication rates of 25-63\% $(14,16)$. In these studies, however, whole liver $\mathrm{RE}$ was uncommon. Moreover, various tumor entities (hepatocellular carcinoma, intrahepatic cholangiocarcinoma, liver metastases) and patients extensively pretreated with chemotherapy were included which limits the clinical validity of those results.

Pathological examination of the livers revealed only little changes to the liver parenchyma following RE. These findings are in accordance to Wang et al. who also have seen only little changes after RE (23). Nonetheless, a mean therapeutic activity of $1,746 \mathrm{MBq}$ was delivered to the livers, which indicates a sufficient treatment of the liver metastases. In this respect, a mean tumor necrosis of $29.4 \%$ was seen. The observed tumor necrosis is in part achieved by $\mathrm{RE}$ as well due to an embolic effects of the spheres, occluding tumor vessels. The spheres can be detected on histopathological slides and are surrounded by tumor necrosis. However, no pronounced inflammation of the tumor free parenchyma was seen. Since only patients were included who did not receive chemotherapy the changes within the analyzed liver specimens are directly associated to RE. Therefore, the present study with a highly selected patient collective indicates that major liver surgery can safely be done even after whole liver RE.

The oncological outcome after liver surgery in NELM depends on multiple factors such as grading, hepatic tumor burden, surgical approach (hepatic tumor clearance $v s$. debulking) and progressive vs. stable disease $(6,24)$. Although not significant, the RE and surgery group had the highest tumor burden and the highest Ki-67 index. Moreover, $75 \%$ had progressive disease at indication for RE. Despite this negative selection the time interval until hepatic progression was not diverging between the surgical patient cohorts. The reported outcome for the RE prior to surgery and the surgery alone group is comparable to the cohorts reported in the literature $(24,26)$. These findings suggest that RE and surgery may have additive therapeutic effects for a selective patient collective. Therefore, RE can be considered as a bridging therapy and downstaging of the metastases can lead to subsequent liver resection. In this respect, RE facilitates to consider patients with diffuse NELM as potential candidates for liver resection. Thus, the multimodal treatment for patients with diffuse progressive NELM seems to be a promising approach and may help to determine tumor biology prior to liver surgery.

Several tumor markers, such as $\mathrm{CgA}$, from patients of group A were analyzed. CgA blood levels correlate with the tumor load and decrease after therapy $(27,28)$. Whereas $\mathrm{RE}$ resulted in intermittent amelioration of $\mathrm{CgA}$, surgery led to a long-lasting reduction of CgA blood levels. This suggests that $\mathrm{RE}$ is an effective therapeutic bridging therapy and should be performed within six months. However, in the case of unexpected contraindications for surgery (i.e., heart failure, restricted lung function) whole liver RE still represents antitumor therapy.

Despite the valuable findings there are several limitations of the present study that have to be considered when interpreting the results. In particular the study group RE followed by surgery is small. Nonetheless, this collective is highly selected including only patients with liver surgery for NELM following RE. Due to the low incidence of NETs with often diffuse NELM, studies about hepatic resection for NELM included small collectives previously $(29,30)$. Thus, the analyzed group of the present manuscript is in line with the literature. The largest previously published study investigating hepatic surgery after RE included 71 patients treated in 16 centers with a wide variety of different tumor entities, which limits clinical relevance of those results (14). Additionally, this is the only study investigating the effect 
of the multimodal therapeutic approach of liver surgery after RE reporting complete information about pre- and postoperative data including pathological examination of the resected livers. Treatment response to RE was evaluated histologically, but radiographic response assessment by MRI or PET/CT has not been performed. Nonetheless, it might be of additional value to evaluate treatment response with ${ }^{68} \mathrm{Ga}$-DOTA-TATE PET/CT or MRI. Recently, Braat et al. demonstrated that response to RE in NET patients can reliably be evaluated with cross-sectional imaging modalities (i.e., CT, MRI) (18). Thus, follow-up of these patients is feasible with widely available imaging modalities. Furthermore, the authors revealed that NELM respond to RE independently of grading and that diffuse hepatic involvement ( $>75 \%$ hepatic tumor load) is associated with a worse outcome, which is in accordance to previous results $(6,24,31)$. Moreover, it was shown that ${ }^{68} \mathrm{Ga}$-DOTATATE PET/CT enables molecular response assessment of NELM to RE (19). Molecular response correlated with survival rates, thus this might be a promising approach identifying patients who will benefit from multimodal treatment, such as liver surgery after RE. Nonetheless, this issue has to be addressed in future studies. Another limitation of our study is that no dosimetric calculation has been performed after RE. The mBSA method has been applied to estimate the delivered activity. This method is feasible and easy to apply and provides the most data in literature (e.g., SIRFLOX and SORAMIC trials) (17,32). Nonetheless, a previsional dose calculation as defined by the Partition Model might have delivered more insight into the therapy and activity concept, but was not performed prior to RE. Thus, one of the limitations of this study is the lack of quantitative dosimetry data after RE, particularly with respect to healthy liver tissue. In the present analysis patients SIR-Spheres distribution after RE was assessed by Bremsstrahlung SPECT/low dose CT and posttherapeutic dosimetry was not performed due to the low diagnostic accuracy of Bremsstrahlung SPECT/CT. In this respect, ${ }^{90}$ Y-PET/CT might be of high value in NET patients with the possibility of surgical liver resection after $\mathrm{RE}$. This issue should be addressed in future multicenter studies on this subject. Treatment algorithms were different regarding the time interval between $\mathrm{RE}$ and liver resection. Nonetheless, the time range between RE and liver surgery might serve as an indicator to safely perform surgery. In this respect, an interval of three months is suggested by the Post-SIR-Spheres Surgery Study group [12], which is supported by the present results. Although baseline characteristics (Table 3) were not different in the analyzed groups, patients who underwent only liver surgery or only $\mathrm{RE}$ represent independent collectives. To define the best treatment algorithm for each patient, the distribution of the metastases (uni- vs. bilobar) is more important than the hepatic tumor load. This has to be considered when a tailor made therapeutic approach is established for a patient with NELM. Survival analyses revealed the most favorable outcome for resected patients. Nonetheless, RE can be used in NELM as bridging therapy and for downstaging.

Despite the numerically limited patients included, this report represents the largest and first study addressing the effect of the multimodal therapeutic approach of liver surgery after RE. Moreover, the feasibility and safety of liver surgery in NELM patients following whole liver RE, which was accompanied by a low morbidity, is analyzed. Within this uniform cohort of NELM the oncological outcome is favorable for patients with complete hepatic tumor clearance. Nonetheless, the role of RE prior to hepatic resection for NELM has to be clarified in prospective multicenter studies.

\section{Acknowledgments}

Funding: None.

\section{Footnote}

Conflicts of Interest: All authors have completed the ICMJE uniform disclosure form (available at https://hbsn.amegroups. com/article/view/10.21037/hbsn.2019.07.11/coif). HI reports speaker honoraria from SIRTEX Medical. CJA has received research contracts (Novartis, Ipsen, ITM Solucin), lecture honorarium (Novartis, Ipsen, Falk Foundation) and advisory board honorarium (Novartis). CS reports personal fees from Ipsen, personal fees from Novartis, personal fees from Shire, personal fees from Blueprint Medicine, personal fees from Bayer, personal fees from Eisai, outside the submitted work. MS reports grants and personal fees from SIRTEX Medical, grants and personal fees from BAYER, personal fees from Siemens, personal fees from Cook, personal fees from Boston Scientific, outside the submitted work. The other authors have no conflicts of interest to declare.

Ethical Statement: The authors are accountable for all aspects of the work in ensuring that questions related to the accuracy or integrity of any part of the work are appropriately investigated and resolved. 
Open Access Statement: This is an Open Access article distributed in accordance with the Creative Commons Attribution-NonCommercial-NoDerivs 4.0 International License (CC BY-NC-ND 4.0), which permits the noncommercial replication and distribution of the article with the strict proviso that no changes or edits are made and the original work is properly cited (including links to both the formal publication through the relevant DOI and the license). See: https://creativecommons.org/licenses/by-nc$\mathrm{nd} / 4.0 /$.

\section{References}

1. Modlin IM, Oberg K, Chung DC, et al.

Gastroenteropancreatic neuroendocrine tumours. Lancet Oncol 2008;9:61-72.

2. Bösch F, Hofmann K, Coenen M, et al. Surgical treatment of pNET - Experience of a "high-volume" center. Surgical Oncol 2018;27:409-14.

3. Saxena A, Chua TC, Sarkar A, et al. Progression and survival results after radical hepatic metastasectomy of indolent advanced neuroendocrine neoplasms (NENs) supports an aggressive surgical approach. Surgery 2011;149:209-20.

4. Arslan N, Emi M, Alagoz E, et al. Selective intraarterial radionuclide therapy with Yttrium-90 (Y-90) microspheres for hepatic neuroendocrine metastases: initial experience at a single center. Vojnosanit Pregl 2011;68:341-8.

5. Pavel M, Baudin E, Couvelard A, et al. ENETS Consensus Guidelines for the management of patients with liver and other distant metastases from neuroendocrine neoplasms of foregut, midgut, hindgut, and unknown primary. Neuroendocrinology 2012;95:157-76.

6. Bosch F, Werner J, Angele MK, et al. Oligometastases of neuroendocrine tumors-extent of surgery. Chirurg 2018;89:516-22.

7. Kennedy AS, Dezarn WA, McNeillie P, et al. Radioembolization for unresectable neuroendocrine hepatic metastases using resin 90Y-microspheres: early results in 148 patients. Am J Clin Oncol 2008;31:271-9.

8. Rajekar H, Bogammana K, Stubbs RS. Selective internal radiation therapy for gastrointestinal neuroendocrine tumour liver metastases: a new and effective modality for treatment. Int J Hepatol 2011;2011:404916.

9. Saxena A, Chua TC, Bester L, et al. Factors predicting response and survival after yttrium-90 radioembolization of unresectable neuroendocrine tumor liver metastases: a critical appraisal of 48 cases. Ann Surg 2010;251:910-6.
10. Hendlisz A, Flamen P, Van den Eynde M, et al. Locoregional and radioisotopic targeted treatment of neuroendocrine tumours. Acta Gastroenterol Belg 2009;72:44-8.

11. Ozao-Choy J, Friedman ML, Kim AS, et al. Radioembolization for treatment of liver metastases from neuroendocrine tumors: correlation with imaging and biomarkers. Pancreas 2013;42:358-60.

12. Vouche M, Lewandowski RJ, Atassi R, et al. Radiation lobectomy: time-dependent analysis of future liver remnant volume in unresectable liver cancer as a bridge to resection. J Hepatol 2013;59:1029-36.

13. Garlipp B, de Baere T, Damm R, et al. Left-liver hypertrophy after therapeutic right-liver radioembolization is substantial but less than after portal vein embolization. Hepatology 2014;59:1864-73.

14. Pardo F, Sangro B, Lee RC, et al. The Post-SIRSpheres Surgery Study (P4S): Retrospective Analysis of Safety Following Hepatic Resection or Transplantation in Patients Previously Treated with Selective Internal Radiation Therapy with Yttrium-90 Resin Microspheres. Ann Surg Oncol 2017;24:2465-73.

15. Braat MN, van Erpecum KJ, Zonnenberg BA, et al. Radioembolization-induced liver disease: a systematic review. Eur J Gastroenterol Hepatol 2017;29:144-52.

16. Wright GP, Marsh JW, Varma MK, et al. Liver Resection After Selective Internal Radiation Therapy with Yttrium-90 is Safe and Feasible: A Bi-institutional Analysis. Ann Surg Oncol 2017;24:906-13.

17. Ricke J, Bulla K, Kolligs F, et al. Safety and toxicity of radioembolization plus Sorafenib in advanced hepatocellular carcinoma: analysis of the European multicentre trial SORAMIC. Liver Int 2015;35:620-6.

18. Braat A, Kappadath SC, Ahmadzadehfar H, et al. Radioembolization with (90)Y Resin Microspheres of Neuroendocrine Liver Metastases: International Multicenter Study on Efficacy and Toxicity. Cardiovasc Intervent Radiol 2019;42:413-25.

19. Filippi L, Scopinaro F, Pelle G, et al. Molecular response assessed by (68)Ga-DOTANOC and survival after (90)Y microsphere therapy in patients with liver metastases from neuroendocrine tumours. Eur J Nucl Med Mol Imaging 2016;43:432-40.

20. Armbruster M, Zech CJ, Sourbron S, et al. Diagnostic accuracy of dynamic gadoxetic-acid-enhanced MRI and PET/CT compared in patients with liver metastases from neuroendocrine neoplasms. J Magn Reson Imaging 2014;40:457-66. 
21. Dindo D, Demartines N, Clavien PA. Classification of surgical complications: a new proposal with evaluation in a cohort of 6336 patients and results of a survey. Ann Surg 2004;240:205-13.

22. Rahbari NN, Garden OJ, Padbury R, et al. Posthepatectomy liver failure: a definition and grading by the International Study Group of Liver Surgery (ISGLS). Surgery 2011;149:713-24.

23. Wang LM, Jani AR, Hill EJ, et al. Anatomical basis and histopathological changes resulting from selective internal radiotherapy for liver metastases. J Clin Pathol 2013;66:205-11.

24. Frilling A, Clift AK. Therapeutic strategies for neuroendocrine liver metastases. Cancer 2015;121:1172-86.

25. Su YK, Mackey RV, Riaz A, et al. Long-Term Hepatotoxicity of Yttrium-90 Radioembolization as Treatment of Metastatic Neuroendocrine Tumor to the Liver. J Vasc Interv Radiol 2017;28:1520-6.

26. Mayo SC, de Jong MC, Pulitano C, et al. Surgical management of hepatic neuroendocrine tumor metastasis: results from an international multi-institutional analysis. Ann Surg Oncol 2010;17:3129-36.

27. Di Giacinto P, Rota F, Rizza L, et al. Chromogranin A: From Laboratory to Clinical Aspects of Patients

Cite this article as: Bösch F, Ilhan H, Pfahler V, Thomas M, Knösel T, Eibl V, Pratschke S, Bartenstein P, Seidensticker M, Auernhammer CJ, Spitzweg C, Guba MO, Werner J, Angele MK. Radioembolization for neuroendocrine liver metastases is safe and effective prior to major hepatic resection. HepatoBiliary Surg Nutr 2020;9(3):312-321. doi: 10.21037/ hbsn.2019.07.11 with Neuroendocrine Tumors. Int J Endocrinol 2018;2018:8126087.

28. Pape UF, Perren A, Niederle B, et al. ENETS Consensus Guidelines for the management of patients with neuroendocrine neoplasms from the jejuno-ileum and the appendix including goblet cell carcinomas. Neuroendocrinology 2012;95:135-56.

29. Clift AK, Frilling A. Management of patients with hepatic metastases from neuroendocrine tumors. Ann Saudi Med 2014;34:279-90.

30. Galleberg RB, Knigge U, Tiensuu Janson E, et al. Results after surgical treatment of liver metastases in patients with high-grade gastroenteropancreatic neuroendocrine carcinomas. Eur J Surg Oncol 2017;43:1682-9.

31. Frilling A, Modlin IM, Kidd M, et al. Recommendations for management of patients with neuroendocrine liver metastases. Lancet Oncol 2014;15:e8-21.

32. Gibbs P, Gebski V, Van Buskirk M, et al. Selective Internal Radiation Therapy (SIRT) with yttrium-90 resin microspheres plus standard systemic chemotherapy regimen of FOLFOX versus FOLFOX alone as firstline treatment of non-resectable liver metastases from colorectal cancer: the SIRFLOX study. BMC Cancer 2014;14:897. 